\title{
Allogeneic hematopoietic stem cell transplantation in children and adults with acute lymphoblastic leukemia*
}

\author{
Sergey N. Bondarenko, Ivan S. Moiseev, Olga A. Slesarchuk, Elena I. Darskaya, Kirill A. Ekushev, Anna G. Smirnova, Al- \\ exander L. Alyanskiy, Tatyana L. Gindina, Elena V. Babenko, Elena V. Kuzmich, Elena V. Semenova, Alexander D. Kulagin, \\ Luydmila S. Zubarovskaya, Boris V. Afanasyev \\ Raisa Gorbacheva Memorial Research Institute for Pediatric Oncology, Hematology and Transplantation, First I.Pavlov State \\ Medical University of St. Petersburg
}

Assistant Professor Sergey N. Bondarenko, Department of Hematology, Transfusion and Transplantation, Faculty of Postgraduate Education, Raisa Gorbacheva Memorial Institute of Children Oncology, Hematology and Transplantation, First I.Pavlov State Medical University, St. Petersburg, Russia, Zaiceva St 3-7, 198096, St. Petersburg, Russia,
Phone: +7 (921) 9943570

Fax: (812) 232-70-06

E-mail: dr.sergeybondarenko@gmail.com

\section{Summary}

The aim of this study was to evaluate efficacy of allogeneic hematopoietic stem cell transplantation (allo-HSCT) in acute lymphoblastic leukemia (ALL), and to specify significant factors affecting clinical outcomes. Patients and methods. The study included 354 ALL patients aged 1 to 61 years who underwent allo-HSCT over a period of 1995 to 2015 . Before HSCT, $24 \%$ of patients were in the 1 st remission, $26 \%$ - in 2 nd remission, $17 \%$, in the $\geq 3 \mathrm{rd}$ remission; $34 \%$ of patients had active disease. Results. Overall survival (OS) was $47 \%$ when HSCT was performed in remission status versus $18 \%$ in patients transplanted in active disease state $(\mathrm{p}<.0001)$. Appropriate relapse incidence (RI) comprised $26 \%$ and $50 \%$, respectively $(\mathrm{P}<.0001)$. Five-year OS was similar in children and adults ( $48 \%$ and $47 \%$ respectively, $\mathrm{p}>0.2$ ). Pre-transplant remission state showed certain correlations with OS in pediatric and adult transplant patients, i.e., $79 \%$ vs $60 \%$ for HSCT in 1 st remission; $40 \%$ vs $43 \%$ in 2 nd remission, and $33 \%$ vs $23 \%$ for the patients treated in $\geq$ 3 rd remission. ALL RI in children and adults were also comparable for HSCT carried out in 1st remission (21\% vs $32 \%$ ), 2 nd remission ( $33 \%$ vs $17 \%$ ), and $17 \%$ vs $23 \%$ for HSCT performed in $\geq 3$ rd remission ( $p>0.2$ ). Most ALL patients underwent myeloablative conditioning regimen (MAC) before allo-HSCT $(n=89)$. OS in MAC group was $53 \%$ versus $40 \%$ among patients who underwent reduced-intensity conditioning (RIC) regimens $(\mathrm{n}=70, \mathrm{p}=0.04)$. The conditioning regimen intensity did not correlate with the RI after allo-HSCT ( $24 \%$ and $30 \%$ (MAC vs RIC respectively), $\mathrm{p}=0.09$ ). Non-relapse mortality (NRM) did not significantly differ for children and adults ( $32 \%$ vs $37 \%, p>0.2$ ), being dependent on the disease state: $21 \%$ vs $25 \%$ after HSCT in the 1 st remission; $31 \%$ and $43 \%$, when treated in the 2 nd remission, and $50 \%$ vs $61 \%$ if transplanted in $\geq 3$ rd remission. Conclusion. Allo-HSCT from an HLA-matched related or unrelated donor is indicated in patients with high-risk ALL in first remission and in all the patients in the second remission.

\section{Keywords}

acute lymphoblastic leukemia, allogeneic bone marrow transplantation, conditioning regimens, survival rates

\footnotetext{
* The paper is based on a presentation at the EWALL meeting (Moscow, 26-27 June 2015)
} 


\section{Introduction}

Acute lymphoblastic leukemia (ALL) represents from 25 to $30 \%$ of all malignancies in childhood, and less common (ca.1\%) in adults. Modern programmed chemotherapy (CT) allows of achieving stable remission in up to $90 \%$ of children and $40 \%$ of adults. However, efficiency of chemotherapy in high-risk ALL patients is still inferior in the both age groups; five-year disease-free survival (DFS) does not exceed $40 \%$ and $25 \%$, respectively $[7,11,12]$.

Allogeneic hematopoietic transplantation (allo-HSCT) is an effective method of treatment for the high-risk ALL patients, both due to a cytostatic effect of conditioning regimen upon leukemic clonogenic cells, and immunoadoptive «graft-versus-leukemia» effect exerted by donor T cells $[1,14]$. However, higher risk of a non-transplant-related mortality (NRM) limits wider application of this treatment modality. High probability of severe graft-versus-host disease (GvHD) is also possible, due to excessive alloreactivity of graft, thus often leading to death [19]. Generally, an increased therapeutic efficiency is observed, due to advent of novel targeted therapies, wider application of reduced-toxicity conditioning (RIC) regimens, and improved quality of supportive care. Therefore, current indications for allo-HSCT in pediatric and adult ALL are subject to permanent revisions [9]. The aim of our study was to evaluate clinical efficacy of allo-HSCT in ALL, and to identify significant factors which may affect general outcome in this clinical setting.

\section{Patients and methods}

The study included 354 patients with ALL ( 1 to 61 years old) who underwent allo-HSCTs from 1995 to 2015.

Age distribution of the patients was as follows: under 10 years, 72 (21\%); 11-20 years, 131 (37\%); 21-30 years, 100 (28\%); $31-40$ years, $29(8 \%)$; over 40 years, $22(6 \%)$. The median age was 22 years.

The patients were classified into distinct cohorts, according to EGIL phenotypic classification, as follows: B-ALL Philadelphia chromosome $(\mathrm{Ph})$-negative was identified in $54 \%$ of total case number including pro-B ALL (23\%), common-B ALL (36\%), pre-B ALL (17\%), mature-B ALL (4\%), B-lineage (20\%). The patients with $\mathrm{Ph}(+) \mathrm{B}$-ALL made up $27 \%$ of total ALL cohort. In this group, we found pro-B ALL (11\%), common-B ALL (70\%), pre-B ALL (4\%), and B-lin (15\%). T-cell ALL was revealed in $19 \%$ of cases: pro-T (12\%); pre-T (44\%); cortic-T (9\%), mature-T (3\%) and T-lineage (32\%).

Primary cytogenetic data were available for $74 \%$ of the patients, and initial molecular biology diagnostics was performed in 57\% of the cases. Cytogenetic and molecular (RTPCR) findings in the patients are shown in Fig. 1 and 2.

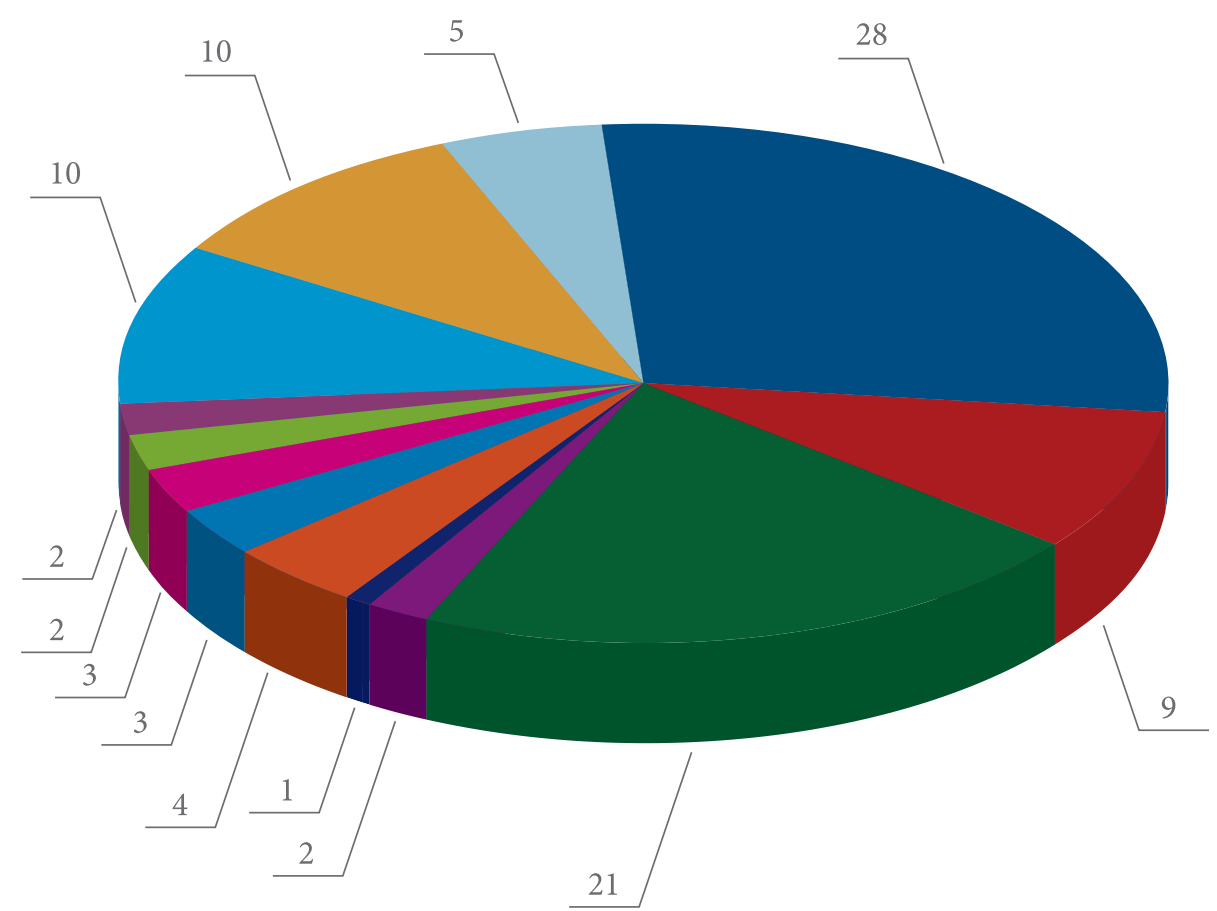

$62 \%$ - unfavorable karyotype

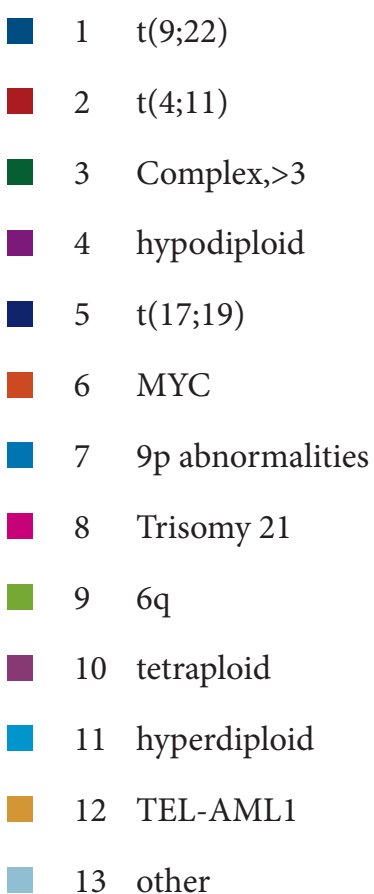




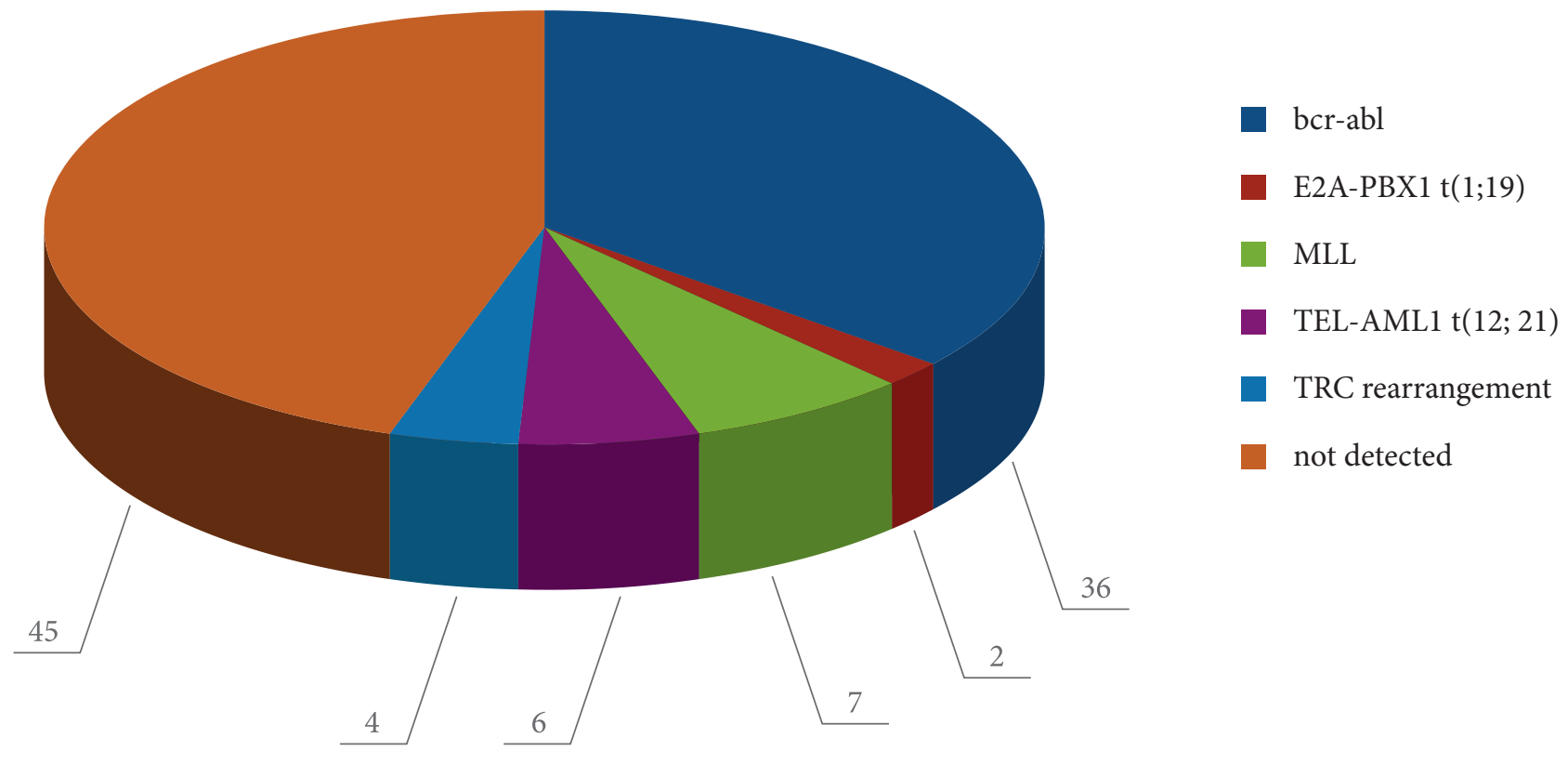

Figure 2. Distribution of patients depending on molecular abnormalities

Indications for allo-HSCT in the $1^{\text {st }}$ remission were as follows: (1) high risk group (leukocytosis $\geq 30.0 \times 10^{9} / \mathrm{L}$ for B-ALL; $\geq$ $100.0 \times 10^{9} / \mathrm{L}$ for T-ALL, BI ALL and TI/TII / T IV EGIL phenotypes; (2) specific chromosome translocations, i.e., $\mathrm{t}(9 ; 22)$ (q34;q11), t(4;11) (q21;q23), or t $8 ; 14)(\mathrm{q} 24.1 ; \mathrm{q} 32)$; complex karyotypic abnormalities $(\geq 5)$, hypodiploid karyotype $(<44$ chromosomes), and/or absence of remission following induction therapy.

Myeloablative conditioning (MAC) included Busulfan $16 \mathrm{mg} / \mathrm{kg}$ and Cyclophosphamide $120 \mathrm{mg} / \mathrm{kg}$. Reduced intensity conditioning (RIC) regimens contained a combination of Fludarabine $\left(150 \mathrm{mg} / \mathrm{m}^{2}\right)$ and Busulfan $(8 \mathrm{mg} / \mathrm{kg})$, or Melphalan $\left(140 \mathrm{mg} / \mathrm{m}^{2}\right)$.

Acute and chronic GVHD prophylaxis included Cyclosporin A, or Tacrolimus combined with Methotrexate $\left(15 \mathrm{mg} / \mathrm{m}^{2}\right.$ on $\mathrm{D}+1$ and $10 \mathrm{mg} / \mathrm{m}^{2}$ on the $\mathrm{D}+3$ and $\left.\mathrm{D}+6\right)$, or Mycophenolate Mofetil (30 mg/kg 2 times daily). GVHD prophylaxis for matched unrelated allo-HSCT was enhanced by antilymphocyte globulin (ATGAM) at a dose of $60 \mathrm{mg} / \mathrm{kg}$. Since 2014, GVHD prophylaxis, especially in haploidentical HSCTs, included Cyclophosphamide (50 mg/kg on D +3 and D + 4 post-transplant).

Conditioning regimens with reduced toxicity were administered to heavily pretreated patients with different complications associated with chemotherapy, subjects over 40 years old and pts with high comorbidity index. General characteristics of recipients, donors and graft properties are shown in Figure 3.

At the time of allo-HSCT, $24 \%$ of patients were in $1^{\text {st }}$ remission, $26 \%$ - in $2^{\text {nd }}$ remission, $17 \%$, in $\geq 3^{\text {rd }}$ remission, whereas $4 \%$ of the patients had active disease.

Statistical evaluation was performed with SPSS Statistics version 17. Overall survival (OS) was calculated with
Kaplan-Meier method, whereas non-relapse mortality (NRM), and relapse incidence (RI) were assessed with $\mathrm{R}$ Statistic software. A log-rank test was used to compare OS, and exact Fisher test was applied for the share analysis. Distinct milestones were taken for evaluation, i.e., dates of birth, HSCT, early death and relapse. Initial terms of acute and chronic GVHD were also taken for clinical analysis. The survivors remaining in remission state by the end of data acquisition were censored by the $01 / 10 / 2015$.

\section{Results}

Five-year OS of patients after allo-HSCT was 47\% if transplanted in remission, as compared to $18 \%$ for the patients who underwent HSCT in active disease ( $\mathrm{p}<0.0001)$, relapse rates were $26 \%$ and $50 \%(\mathrm{P}<0.0001)$, respectively (Fig. 4 ).

Further analysis was performed for those patients who were in remission at the time of allo-HSCT $(n=159)$. The type of ALL has no effect on overall and event-free survival. Fiveyear OS of children and adults was $48 \%$ and $47 \%(\mathrm{p}>0.2)$.

The disease state pre-transplant exerted some influence upon the OS rates in children and adults, i.e., $79 \%$ vs $60 \%$ for allo-HSCT in $1^{\text {st }}$ remission; $40 \%$ vs $43 \%$ in $2^{\text {nd }}$ remission, and $33 \%$ vs $23 \%$ for the patients treated in $\geq 3^{\text {rd }}$ remission (Fig. 5). The RI after allo-HSCT in children and adults were also comparable for patients transplanted in the $1^{\text {st }}$ remission ( $21 \%$ vs $32 \%), 2^{\text {nd }}$ remission ( $33 \%$ vs $\left.17 \%\right)$, and $17 \%$ vs $23 \%$ for the patients transplanted in $\geq 3^{\text {rd }}$ remission ( $p>0.2$ ). Type of the donor and source of the graft did not affect OS. However, OS in cases of allo-HSCT from HLA-matched donor was higher than from HLA-mismatch donor (51\% vs $25 \%, p=0.002$ ), as seen from Fig. 6. Moreover, OS rate after allo-HSCT from matched related donors was $62 \%$, from unrelated donors - 44\%, from unrelated HLA-mismatched donors - $25 \%(\mathrm{p}>0.07)$. 


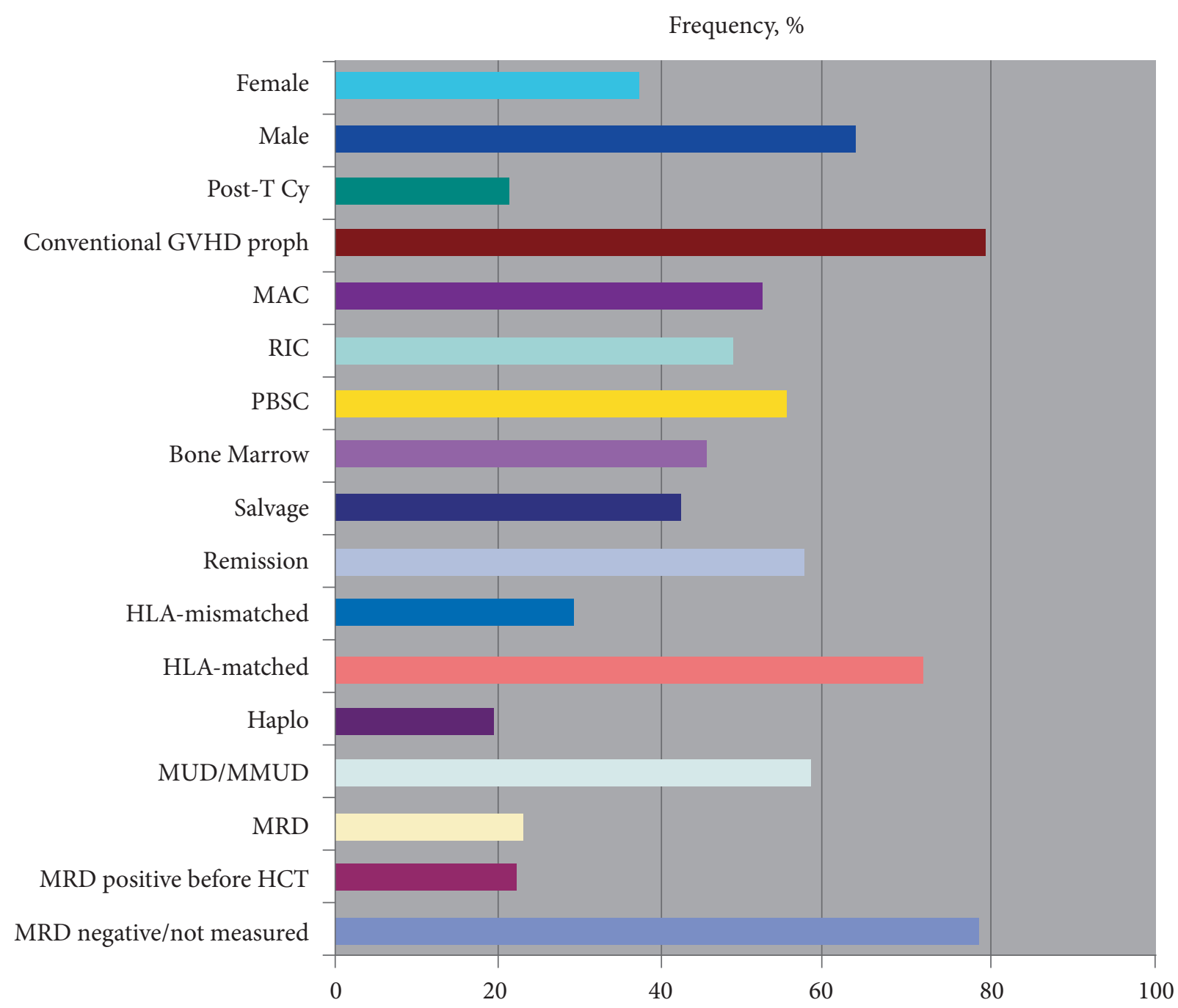

Figure 3. Characteristics of recipients, donors and transplant types
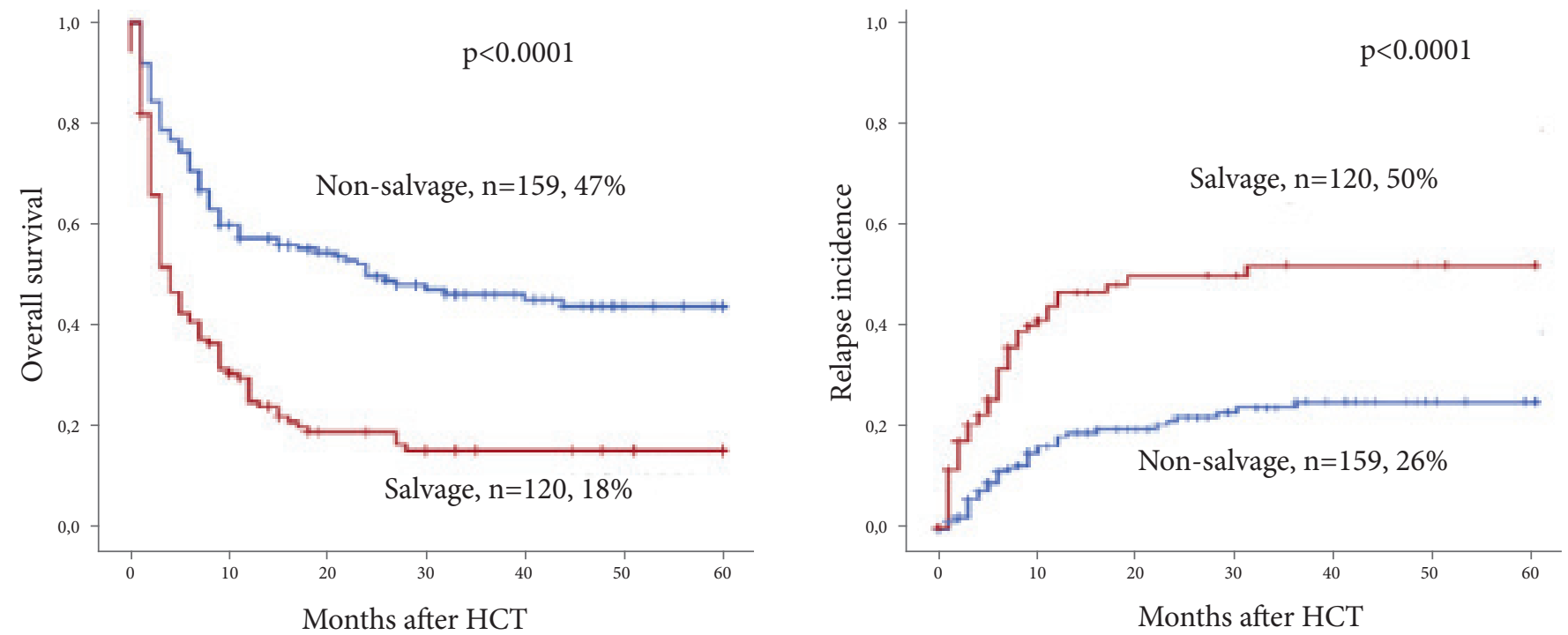

Figure 4. Overall survival and relapse incidence after allo-HSCT 

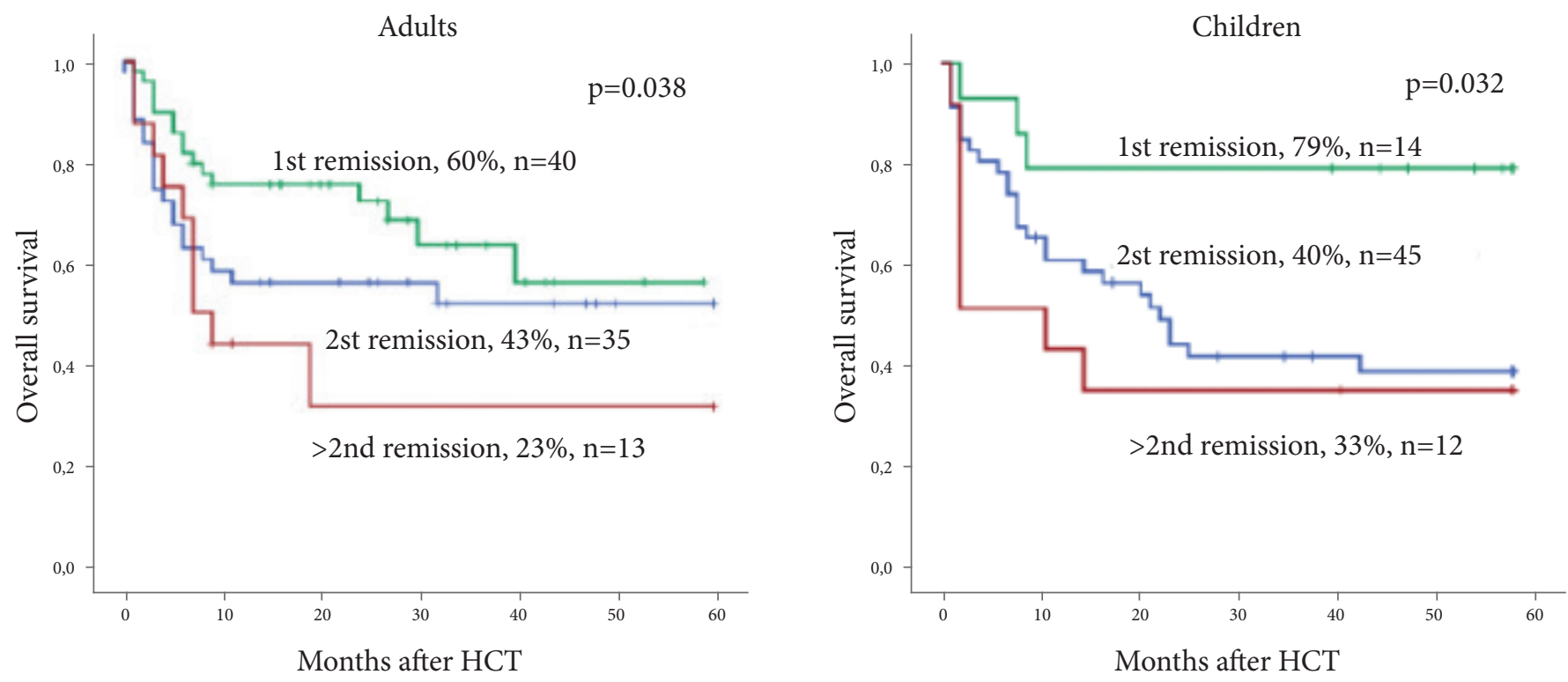

Figure 5. Overall survival in pediatric and adult ALL depending on the disease status at the time of allo-HSCT
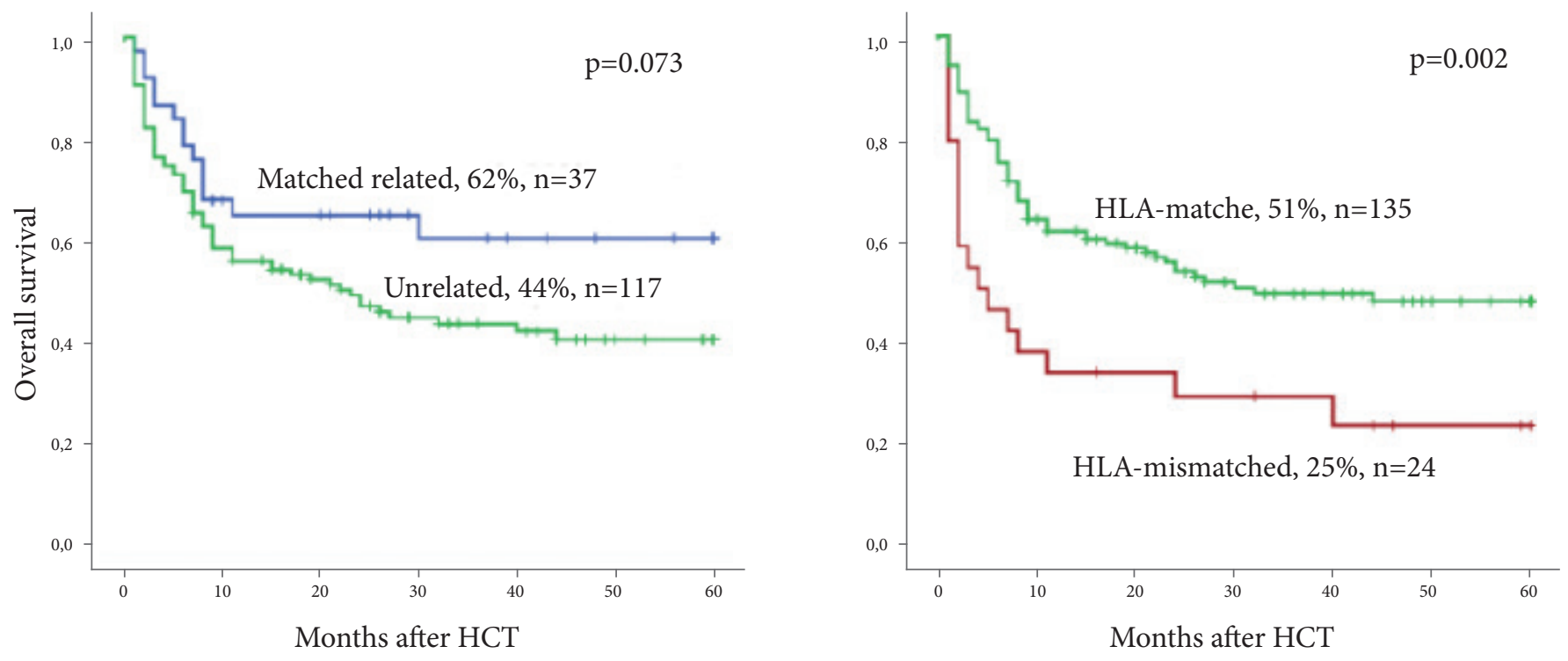

Figure 6. Overall survival after allo-HSCT depending on the donor type and HLA-compatibility of the donor and recipient

Most patients received MAC regimens $(n=89)$. OS in this group was $53 \%$ vs $40 \%$ in RIC group ( $\mathrm{n}=70, \mathrm{p}=0.04)$. Intensity of the conditioning regimen did not show statistically significant impact on the NRM (28\% and 35\%, p=0.06) and on the RI ( $24 \%$ and $30 \%$ respectively, $\mathrm{p}=0.09$ ).

$\mathrm{RI}$ in children and adults were also comparable when treated in the $1^{\text {st }}$ remission $-21 \%$ and $32 \%$, when transplanted in the $2^{\text {nd }}$ remission $-33 \%$ and $17 \%$, if treated in the $\geq 3^{\text {rd }}$ remission, $17 \%$ and $23 \%$ respectively, $\mathrm{p}>0.2$. In our study the RI differed for distinct cytogenetic risk groups: in high risk group it was $36 \%$, in the intermediate-risk group, $31 \%$, $\mathrm{p}=0.2$ (Fig. 7). In most cases, a relapse occurred within $1^{\text {st }}$ year after allo-HSCT (57\%). In some patients with early ALL relapse, clonal evolution was detectable, i.e., emergence of new cytogenetic abnormalities (Table 1).

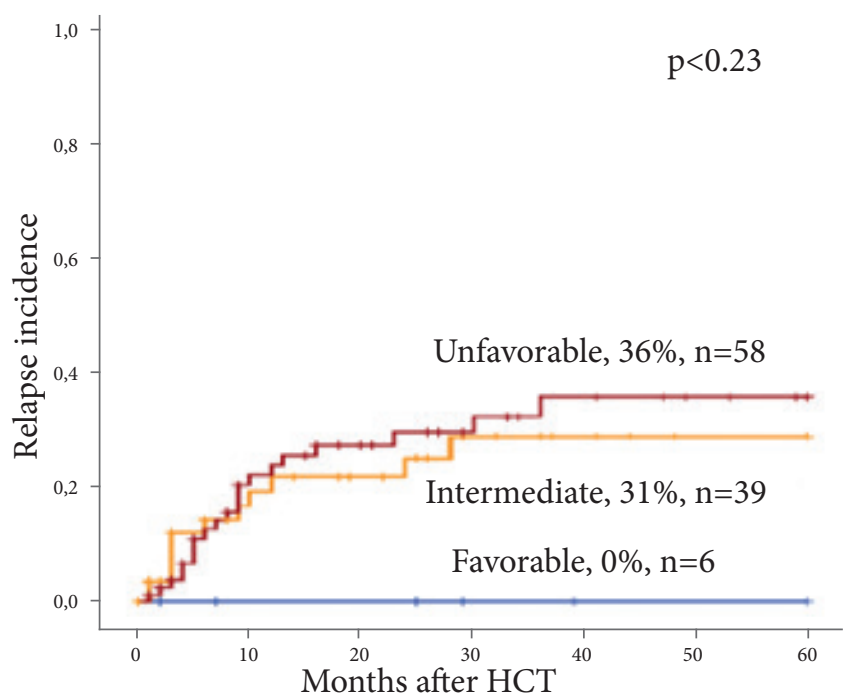

Figure 7. The influence of cytogenetic risk group at the relapse incidence 
Table 1. Post-transplant evolution of leukemia clones in relapsed ALL

\begin{tabular}{|c|c|c|}
\hline № & Before HCT & Relapse after HCT \\
\hline $\begin{array}{l}1 \\
\mathrm{~m}_{1} \\
42\end{array}$ & $\begin{array}{l}46, X Y, t(9 ; 22)(q 34 ; q 11) \\
t(2 ; 7)(p 21 ; 22), \\
\operatorname{add}(21)(q 22) \\
\operatorname{add}(22)(p 13)\end{array}$ & $\begin{array}{l}\text { idem, der(1)t(1;?)(q21;?), } \\
\text { add(1)(q34), add(4)(p16), } \\
\text { der(5)t(5;?)(q31;?)x2, add(7) } \\
\text { (p22),del(11)(q23), add(14) } \\
\text { (p11), }\end{array}$ \\
\hline $\begin{array}{l}2 \\
f_{1} \\
37\end{array}$ & $\begin{array}{l}47, X X \\
t(9 ; 22)(q 34, q 11)+P h\end{array}$ & $\begin{array}{l}47, X X, \operatorname{der}(6) t(6 ; 12 ; 13), \\
\operatorname{del}(13)(q 13),-9, \operatorname{der}(12) \\
\mathrm{t}(6 ; 12), \\
+\operatorname{der}(22) \mathrm{t}(9 ; 22),+22\end{array}$ \\
\hline $\begin{array}{l}3 \\
f_{1} \\
30\end{array}$ & $\begin{array}{l}46, X Y, t(9 ; 22) \\
\text { (q34;q11), } \\
\text { del(12)(p12p13) }\end{array}$ & $\begin{array}{l}\text { idem, i(8)(q10),add(11)(p13), } \\
\text { add(15)(p11) }\end{array}$ \\
\hline
\end{tabular}

Immunoadoptive therapy (donor lymphocyte infusions) was carried out in 73 patients (20\%) for prevention and/or treatment of relapses. Seventeen patients received DLI as monotherapy. For 56 patients, DLI was applied in combination with cy-

\begin{tabular}{|c|c|c|}
\hline № & Before HCT & Relapse after HCT \\
\hline $\begin{array}{l}4 \\
f_{1} \\
13\end{array}$ & $\begin{array}{l}48, X Y, a d d(5) \\
(q 35), t(9 ; 22) \\
(q 34 ; q 11),+17, i(17) \\
(q 10)_{,}+19\end{array}$ & $\begin{array}{l}\text { 49,XY, }+X, \operatorname{del}(2)(q 33), \\
+5, \operatorname{del}(5)(q 15 q 33),+8, \\
t(9 ; 22)(q 34 ; q 11), \operatorname{del}(11) \\
(p 15), \operatorname{add}(19)(q 13)\end{array}$ \\
\hline $\begin{array}{l}5 \\
m_{1} \\
8\end{array}$ & $46, X X, t(4 ; 11)(q 21 ; q 23)$ & $\begin{array}{l}46, X X, \operatorname{der}(3) t(1 ; 3) \\
(q 12 ; p 25), t(4 ; 11)(q 21 ; q 23), i(7) \\
(q 10)\end{array}$ \\
\hline $\begin{array}{l}6 \\
\mathrm{f}, 10\end{array}$ & $50, X_{1}+X_{1}+14_{1}+21,+21$ & $\begin{array}{l}51, X Y_{1}+X_{1}+8++14, \text { add }(19) \\
(\mathrm{p} 13)_{1}+21,+21\end{array}$ \\
\hline $\begin{array}{l}7 \\
\mathrm{~m}, 16\end{array}$ & $46, X X, t(4 ; 11)(q 21 ; q 23)$ & $\begin{array}{l}47, \mathrm{XX},+\mathrm{X}_{1}+\mathrm{i}(3)(\mathrm{q} 10), \mathrm{t}(4 ; 11) \\
\text { (q21;;q23),del(16)(p13),- } \\
\text { 17,add(21)(q22) }\end{array}$ \\
\hline
\end{tabular}

toreductive chemotherapy, tyrosine kinase inhibitors (TKI), or recombinant interleukin-2. The overall response rate was 38\% (Table 2). Preventive DLI tended to be more effective than therapeutic one (respectively, $52 \%$ vs $31 \%$, $\mathrm{p}=0.08$ ).

Table 2. Efficacy of donor lymphocyte infusions after allo-HSCT

\begin{tabular}{|l|l|l|l|l|l|}
\hline & \multicolumn{4}{|l|}{ Efficacy } & \multicolumn{2}{|l|}{} \\
\hline Diagnosis & ALL (n=73) & AML+MDS (n=112) & HD (n=16) & $\begin{array}{l}\text { NHL } \\
(\mathrm{n}=20)\end{array}$ & CML (n=22) \\
\hline Overall response rate & $\begin{array}{l}38 \% \\
(28 / 73)\end{array}$ & $44 \%(49 / 112)$ & $44 \%(7 / 16)$ & $\begin{array}{l}45 \% \\
(9 / 20)\end{array}$ & $59 \%(13 / 22)$ \\
\hline Preemptive DLI (MRD/falling chimer) & $\begin{array}{l}52 \% \\
(13 / 25)\end{array}$ & $35 \%(9 / 26)$ & $n 0$ & $2 / 2$ & $78 \%(7 / 9)$ \\
\hline Therapeutic DLI (relapse/progression) & $\begin{array}{l}31 \% \\
(15 / 48)\end{array}$ & $46 \%(40 / 86)$ & $44 \%(7 / 16)$ & $39 \%(7 / 18)$ & $46 \%(6 / 13)$ \\
\hline
\end{tabular}

Non-relapse mortality did not differ between children and adults ( $32 \%$ vs. $37 \%, \mathrm{p}>0.2)$, being also dependent on the pre-transplant disease stage, i.e., $21 \%$ and $25 \%$ for the $1^{\text {st }}$ remission, $31 \%$ and $43 \%$, for the $2^{\text {nd }}$ remission; $50 \%$ and $61 \%$ for the $\geq 3^{\text {rd }}$ remission (Fig. 8).

Acute GVHD was noted in $34 \%$ of patients, including clinically severe complications (grade III to IV) observed in $13.8 \%$ of patients. No statistically significant differences in acute GVHD incidence were revealed between the groups of related and unrelated allo-HSCT $(\mathrm{p}=0.1)$.

Chronic GVHD after allo-HSCT was evaluated in patients surviving more than 100 days. The incidence of chronic GVHD was $40.9 \%$, including extended clinical forms (33.4\%). OS rate among patients with chronic GVHD was
$68 \%$, as compared to the patients free of chronic GVHD $(52 \%, \mathrm{p}=0.03)$.

In multivariate analysis, only ALL phenotype $(\mathrm{Ph}(+) \mathrm{B}$-ALL and T-ALL vs Ph (-) B-ALL [2.21 (95\% CI 1.3-3.4), $\mathrm{p}=0.05$ ] and acute GVHD [grade 0-1 versus grade 2-4: 1.49 (95\% CI $0.9-2.8), \mathrm{p}=0.04]$ influenced the RI values.

\section{Discussion}

In our study, patient age (children/adults) had no effect on OS, EFS, RI and incidence of GVHD. Disease state at the time of allo-HSCT showed the greatest impact upon OS ( $47 \%$ when transplanted in remission $v s$ 18\%, in active disease), and upon RI, thus being in accordance with similar results of e.g., F. Hutchinson Cancer Research Center: dis- 

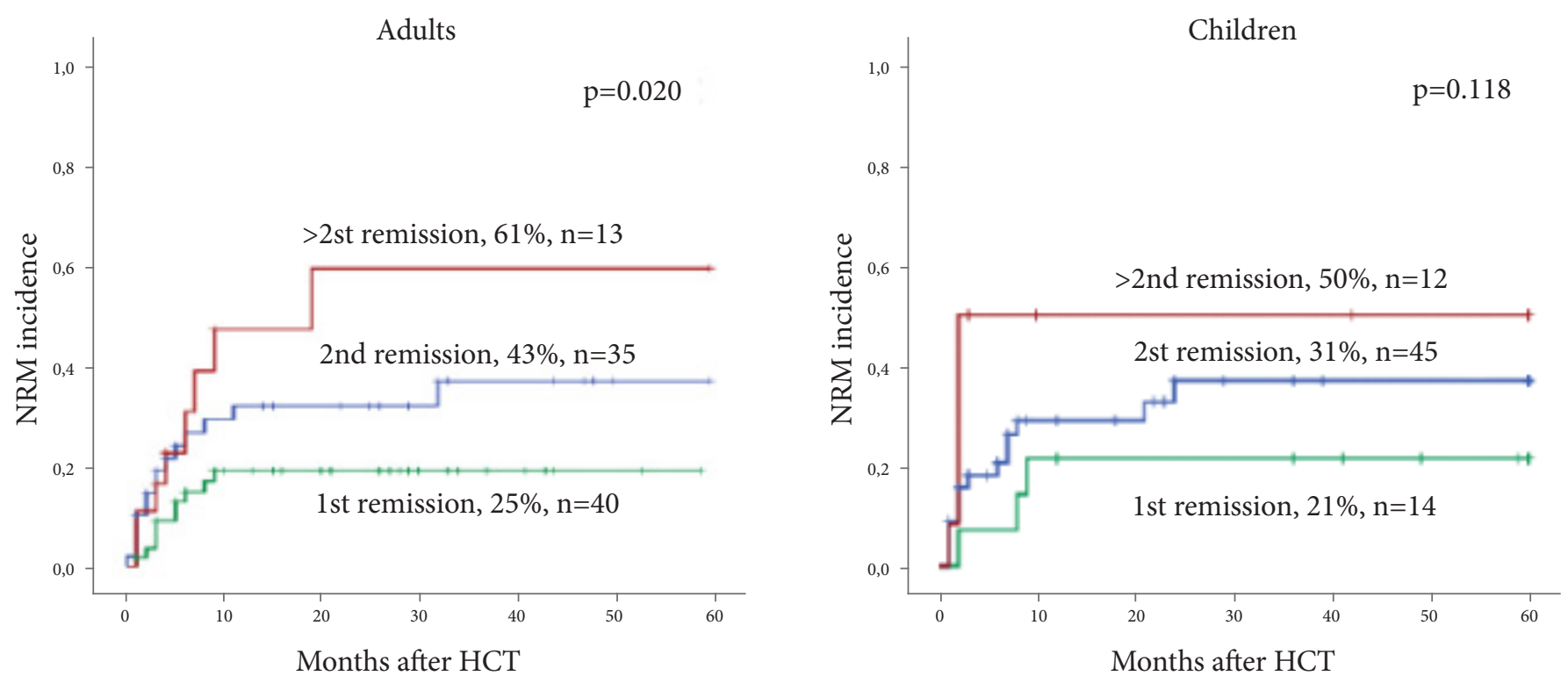

Figure 8. Non-relapse mortality compared in pediatric and adult ALL depending on the disease status before alIo-HSCT

ease-free survival was $33 \%$ vs $9 \%$, and relapse rates - $22 \%$ vs $45 \%$ [5]. The number of previous treatment cycles before allo-HSCT was also of sufficient importance. Both OS overall survival and RI were the highest after HSCT in the $1^{\text {st }}$ remission, with decreased survival for the patients treated in $2^{\text {nd }}$ or $3^{\text {rd }}$ remission, along with lower NRM rates. This trend is in accordance with results obtained by other researchers, where the patients in $1^{\text {st }}$ and in the $2^{\text {nd }}$ remission showed a sufficient difference in relapse risk $[6,10,18]$.

More recently, a distinct trend is seen towards allo-HSCT in other ALL patients than those with high-risk cytogenetics. In the study of the Dutch-Belgian HOVON cooperative group, the comparisons were made between the patients with/without available donors. Allo-HSCT has shown to benefit the patients from both high and standard-risk groups. For standard risk group, the OS rates were $69 \%$ versus $49 \%(\mathrm{p}<0.05)$ and RI, $14 \%$ vs $52 \%$ ( $\mathrm{p}<0.001)$. Appropriate levels for the high-risk groups were $53 \%$ vs $41 \%(\mathrm{p}=0.5)$, and $34 \%$ vs $61 \%$, $\mathrm{p}=0.03$, respectively [4]. In our study, however, the OS and RI proved to be similar for high and standard-risk ALL.

The disease relapse after allo-HSCT has significant impact upon outcomes. Early detection of the minimal residual disease and/or falling donor chimerism after allo-HSCT, especially in high risk group patients, may be a clinical indication for DLI and/or target therapy (TKI, blinatumomab) [13]. Although DLI has limited benefit in ALL [3, 17], our data demonstrated that preventive DLI may be more effective than therapeutic DLI.

Sufficient HLA-incompatibility between the donor and recipient, both for major and minor antigens, is also known the exert a negative effect on the results of allo-HSCT, by association of severe immunological complications which enhance mortality of patients $[8,20]$. It was also confirmed by our results obtained in the groups with different types of HSC donors. Reduced intensity of conditioning regimens did not affect the RI, due to immunoadoptive graft-versus-leukemia effect and usage of donor lymphocyte infusions for prophylactic and preventive purposes $[9,15,16]$.

In some patients who had no available HLA-matched donors, the HSCs were taken from haploidentical family members. Most of the patients treated with haplo-HSCT exhibited active malignant disease at the time of allo-HSCT, and the disease progression after allo-HSCT was a main cause of death. Noteworthy, we didn't observe any uncontrolled severe GVHD in this group. In our experience, haplo-HSCT is a promising approach with post-transplant cyclophosphamide used for the GVHD prophylaxis in the patients with very high risk and late relapses. These data correspond to a study published by Bacigalupo et al. [2]. The authors have shown that mortality in this setting was, mainly, due to malignancy relapse (22\%), whereas fatal GVHD was diagnosed only in $2 \%$.

\section{Conclusions}

Allo-HSCT from an HLA-matched related or unrelated donor is recommended for the patients with high-risk ALL in the $1^{\text {st }}$ remission, and for all patients in the $2^{\text {nd }}$ remission. Due to advent of new drugs (targeted therapy, monoclonal antibodies) the indications for allo-HSCT are constantly changing. In adult patients, a trend for transplantation in the $2^{\text {nd }}$ remission is evident, thus corresponding to appropriate recommendations for children. An additional criterion for allogeneic transplantation is the $1^{\text {st }}$ remission and grafting from HLA-mismatched or alternative donor is a high level of minimal residual disease, thus requiring further research.

\section{Conflict of interest}

None declared 


\section{References}

1. Afanasyev BV, Zubarovskaia LS, Semenova EV, Ivanova NE, Alianskiǐ AL, Morozova EV, Mikhaǔlova NB, Darskaia EI, Estrina MA, Golovacheva AA, Babenko EV, Bondarenko SN, Ganapiev AA, Bogomol'nyı̆ MP. Experience of non-related allogeneic transplantation of stem hematopoietic cells in the Clinic of Bone Marrow Transplantation at I.P. Pavlov St.Petersburg Medical University. Terapevticheskyi Archiv 2007; 79 (7):36-43 (In Russian).

2. Bacigalupo A, Dominietto A, Ghiso A, Di Grazia C, Lamparelli T, Gualandi F, Bregante S, Van Lint MT, Geroldi S, Luchetti S, Grasso R, Pozzi S,Colombo N, Tedone E, Varaldo $\mathrm{R}$, Raiola AM. Unmanipulated haploidentical bone marrow transplantation and post-transplant cyclophosphamide for hematologic malignanices following a myeloablative conditioning: an update. Bone Marrow Transplant 2015; 50 (Suppl 2): S37-39.

3. Collins RH Jr, Goldstein S, Giralt S, Levine J, Porter D, Drobyski W, Barrett J, Johnson M, Kirk A, Horowitz M, Parker P. Donor leukocyte infusions in acute lymphocytic leukemia. Bone Marrow Transplant. 2000; 26 (5): 511-516.

4. Cornelissen JJ, van der Holt B, Verhoef GEG, van 't Veer $\mathrm{MB}$, van Oers MHJ, Schouten HC, Ossenkoppele G, Sonneveld P, Maertens J, van Marwijk KM, Schaafsma MR, Wijermans PW, Biesma DH, Wittebol S, Voogt PJ, Baars JW, Zache'e P, Verdonck LF, Loewenberg D, Dekker AW. Myeloablative allogeneic versus autologous stem cell transplantation in adult patients with acute lymphoblastic leukemia in first remission: a prospective sibling donor versus no-donor comparison. Blood 2009; 113:1375-1382.

5. Doney K, Haegglund H, Leisenring W, Chauncey T, Appelbaum FR, Storb R. Predictive factors for outcome of allogeneic hematopoietic cell transplantation for adult acute lymphoblastic leukemia. Biol Blood Marrow Transplant 2003; 9 (7):472-481.

6. Doney K, Gooley TA, Deeg HJ, Flowers MED, Storb R, Appelbaum FR. Allogeneic hematopoietic cell transplantation with full-intensity conditioning for adult acute lymphoblastic leukemia: results from a single center, 1998-2006. Biol Blood Marrow Transplant. 2011; 17 (8): 1187-1195.

7. Karachunsky AI, Roumyantseva YuV, Roumyantsev AG. Treatment evolution of pediatric acute lymphoblastic leukemia: critical application of international experience in Russia. Voprosy Gematologii/Oncologii I Immunopatologii v Pediatrii 201110 (2): 15-31 (In Russian).

8. Kuzmich EV, Makarenko OA, Alynskiy AA, Timofeeva NP, Ivanova NE, Bondarenko SN, Zubarovskaya LS, Afanasyev BV. Impact of matching of HLA class I and class II alleles in the donor and recipient on the risk graft-versushost disease after unrelated allogenic HSCT: a single center experience. Hum Immunol 2013; 74 (Suppl. 1): 122.

9. Mohty M, Labopin M, Volin L, Gratwohl A, Socié G, Esteve J, Tabrizi R, Nagler A, Rocha V. Reduced-intensity versus conventional myeloablative conditioning allogeneic stem cell transplantation for patients with acute lympho- blastic leukemia: a retrospective study from the European Group for Blood and Marrow Transplantation. Blood 2010; 116:4439-4443.

10. Nishiwaki S, Miyamura K, Ohashi K, Kurokawa M, Taniguchi S, Fukuda T, Ikegame K, Takahashi S, Mori T, Imai K, Iida $H$, Hidaka M, Sakamaki H, Morishima Y, Kato K, Suzuki R, Tanaka J. Impact of a donor source on adult Philadelphia chromosome-negative acute lymphoblastic leukemia: a retrospective analysis from the Adult Acute Lymphoblastic Leukemia Working Group of the Japan Society for Hematopoietic Cell Transplantation. Ann Oncol 2013; 24:1594-1602.

11. Parovichnikova EN, Davidyan YuR, Domracheva EV, Bondarenko SN, Kaporskaya TS, Ryltsova TV, Kondakova EV, Baranova OYu, Savchenko VG. Detection of chromosomal aberrations determines the disease diagnosis in adult patients with $\mathrm{Ph}$-negative acute lymphoblastic leukemia: results of Russian Multicentric Study - RALL Group. Gematologiya i Transfusiologiya 2012; 57 (3):18-19 (In Russian).

12. Pui CH, Carroll WL, Meshinchi S, Arceci RJ. Biology, risk stratification, and therapy of pediatric acute leukemia: An update. J Clin Oncol 2011; 29:551-565.

13. Pulsipher MA, Bader P, Klingebiel T, Cooper LJ. Allogeneic transplantation for pediatric acute lymphoblastic leukemia: the emerging role of peritransplantation minimal residual disease/chimerism monitoring and novel chemotherapeutic, molecular, and immune approaches aimed at preventing relapse. Biol Blood Marrow Transplant. 2009; 15 (1 Suppl): 62-71.

14. Roumyantsev AG, Maschan AA. Hematopoietic Stem Cell Transplantation in Children. A Doctors' Manual. MIA Publishers, Moscow, 2003, 912 p. ((In Russian).

15. Semenova EV, Stancheva NV, Bondarenko SN, Vavilov VN, Bagge DA, Paina OV, Rasumova SV, Borovkova AS, Bykova TA, Rats AA, Zoubarovskata LS, Afanasyev BV. Treatment of refractory acute lymphoblastic leukemia in children and adolescents: remission reinduction followed by allogeneic hematopoietic stem cell transplantation. Klinicheskaya Onkogematologyia 2013; 6 (1): 53-58 (In Russian).

16. Slesarchuk OA, Babenko EV, Semenova EV, Bondarenko SN, Éstrina MA, Morozova EV, Paina OV, Vavilov VN, Smirnov BI, Zubarovskaia LS, Afanasyev BV. Efficiency of donor lymphocyte infusions in patients following different types of hematopoietic stem cell transplantation. Terapevticheskyi Archiv 2013; 85 (7): 26-33 (In Russian).

17. Spyridonidis A, Labopin M, Schmid C, Volin L, Yakoub-Agha I, Stadler M, Milpied N, Socie G, Browne P, Lenhoff S, Sanz MA, Aljurf M, Mohty M, Rocha V; Immunotherapy Subcommittee of Acute Leukemia Working Party. Outcomes and prognostic factors of adults with acute lymphoblastic leukemia who relapse after allogeneic hematopoietic cell transplantation. An analysis on behalf of the Acute Leukemia Working Party of EBMT. Leukemia. 2012; 26 (6):1211-1217.

18. Sureda A, Bader P, Cesaro S, Dreger P, Duarte RF, Dufour C, Falkenburg JH, Farge-Bancel D, Gen- 
nery A, Kröger N, Lanza F, Marsh JC, Nagler A, Peters C, Velardi A, Mohty M, Madrigal A. Indications for allo- and auto-SCT for haematological diseases, solid tumours and immune disorders: current practice in Europe, 2015. Bone Marrow Transplant 2015: 50 (8):1037-1056.

19. Tracey J, Zhang MJ, Thiel E, Sobocinski KA, Eapen M. Transplantation conditioning regimens and outcomes after allogeneic hematopoietic cell transplantation in children and adoltscents with acute lymphoblastic leukemia. Biol Blood Marrow Transplant 2013; 19:255-259.

20. Wang TF, Huang $\mathrm{H}$, Tzeng $\mathrm{CH}$, Wang PN, Wu T, Sun J, Tang JL, Hu J, Lin SF, Kao RH. Impact of donor characteristics and HLA matching on survival of Chinese patients with hematologic malignancies undergoing unrelated hematopoietic stem cell transplantation. Biol Blood Marrow Transplant 2012; 18 (12):1939-1944. 